\title{
Adherence to antiretroviral therapy among pregnant women infected with HIV-1 in early childhood
}

\author{
Eugenia-Andreea Marcu ${ }^{1,2}$, Mariana Stanescu ${ }^{1,2}$, Costin Berceanu ${ }^{1,3}$, \\ Florentina Dumitrescu ${ }^{1,2}$ \\ ${ }^{1}$ University of Medicine and Pharmacy, Craiova, Romania \\ 2"Victor Babes" Clinical Hospital of Infectious Diseases and Pneumoftiziology, Craiova, Romania \\ ${ }^{3}$ Emergency Clinical County Hospital, Craiova, Romania
}

\begin{abstract}
Objectives. To assess the level of adherence to combined antiretroviral therapy (cART) among pregnant women infected with HIV-1 in early childhood, registered in Craiova Regional Center for Monitoring and Evaluation of HIV / AIDS within „Victor Babes” Clinical Hospital of Infectious Diseases and Pneumoftiziology of Craiova (CRC) and to identify the main factors associated with non-adherence.

Material and method. Retrospective study, during January 1st 2014 and December 31st 2019, with the analysis of the data mentioned in the medical records for the HIV-positive pregnant women registered within CRC.

The level of adherence was assessed after applying an adherence questionnaire: 18-22 points (adherence $\geq 80 \%$ ) and under 18 points (non-adherence $<80 \%$ ).

Results. The studied group included 71 patients and it was divided into two batches, depending on the route of HIV transmission: group A which included 48 pregnant women parenterally infected with HIV in early childhood and 23 pregnant women sexually infected with HIV.

We found that the proportion of non-adherent patients was higher in sexually infected mothers $(77.7 \%)$ compared to those parenterally infected, in early childhood (14.8\%), with statistically significant differences $(p=0.001)$. The HIV viral load level was correlated with the level of adherence to cART $(p=0.005)$.

Conclusions. Pregnant women infected with HIV-1 in early childhood had a higher level of adherence to CART compared to those sexually infected, directly correlated with HIV viremia.
\end{abstract}

Keywords: HIV, adherence, parenteral, early childhood

\section{INTRODUCTION}

At the end of 2019, the number of women infected with the human immunodeficiency virus (HIV) globally was about 19.6 million. Approximately 14 million of these women give birth every year and $82 \%$ receive combined antiretroviral therapy (cART) (1).

cART during pregnancy should focus on the reduction of perinatal transmission and the treatment of maternal disease (2).
cART can reduce perinatal transmission by lowering maternal antepartum HIV viral load (VL-HIV) and pre-exposure prophylaxis of the newborn (3).

In high-income countries, the implementation of cART has reduced the rate of mother-to-child transmission of HIV infection to less than 1-2\%, with extremely low rates in women under cART at the time of conception (for instance $0.2 \%$ in France from 2000 to 2010). In middle- and low-income countries, clinical 
trials have shown rates of maternal-fetal transmission less than 5\% (4-6).

As part of the effort to eliminate maternal-fetal transmission of HIV, the World Health Organization (WHO) introduced in 2010 two options, designed to prevent the mother-to-chlid transmission of HIV infection, option A and option B. Under option A, two distinctly antiretroviral regimens were prescribed for pregnant or breastfeeding women based on their clinical and immunological status, while under option B, triple antiretroviral therapy is prescribed to all HIVinfected pregnant or breastfeeding women (7).

When choosing the therapy, the following should be considered: safety profile, possible side effects, frequency of administration, lack of teratogenicity, VL-HIV at initiation, genotypic resistance threshold, maternal comorbidities, presence of HLA B 5701 (8). Many physiologic changes during pregnancy (volume expansion, gastrointestinal, enzymatic and hormonal changes) may also affect the pharmacokinetic properties of antiretrovirals and may alter drug absorption, reduce maternal albumin binding and increase the excretion (9).

Women who are already on ARTc when pregnancy occurs should continue their regimens if they are effective, maintain viral supression and don't include drugs that are contraindicated in pregnancy (8).

While ARTc has improved dramatically the clinical status of many pregnant women HIV infected, the attention is increasingly focusing on the role of treatment adherence. Evidence shows that poor adherence to antiretroviral regimens has serious consequences on the health of the mother and her unborn baby. It has been estimated that if pregnant women adhere at least 95\% this maximizes the benefits of cART and improves the virological, immunological and clinical outcomes (10).

Adherence to treatment implies a collaboration between the patients and the medical staff and represents the correct employment and participation of the patient in the treatment plan. However, adherence to cART continues to be a major public health concern. Various studies have shown that virologic and clinical success depends on good adherence to cART. With low adherence, the virus quickly develops therapylimiting drug resistance (11).

High-levels of sustained adherence in pregnant women are directly associated with low risk of motherto-chlid transmission of HIV infection, viral load suppression and increased life expectancy in the mother. In contrast, poor adherence to cART has been associated with poor treatment outcomes, emergence of resistance, increased healthcare costs and avoidable deaths (12).

The main factors that can affect the adherence to ARTc include: ARTc side-effects, social stigma, depression, non-disclosure of HIV status, unemployment, alcohol/substance abuse, alternative forms of therapy, stock outs and distance to clinics $(13,14)$. The factors associated with non-adherence also vary contextually (for instance, lack of education, younger age, rural residence, lack of emotional and financial support from family) (15).

Knowing their HIV status before pregnancy is an important factor that influences the adherence to cART of the patients.

Although there is a possibility of an increased risk of preterm delivery in pregnant women receiving cART, there are clear benefits of cART for the prevention of mother-to-child transmission and maternal health and the treatment must be started and continued during pregnancy (16).

The objectives of this study are to are to assess the level of adherence to cART among pregnant women infected with HIV-1 in early childhood, registered in Craiova Regional Center for Monitoring and Evaluation of HIV / AIDS within „Victor Babes” Clinical Hospital of Infectious Diseases and Pneumoftiziology of Craiova (CRC) and to identify the main factors associated with non-adherence.

\section{MATERIAL AND METHODS}

We conducted a retrospective study, during January $1^{\text {st }} 2014$ and December $31^{\text {st }} 2019$, with the analysis of the data mentioned in the medical records for the HIV-positive pregnant women registered within CRC.

We evaluated the demographic data, epidemiological data, data on antiretroviral treatment (duration of administration, number and type of regimen used), data provided by the results of the cART adherence questionnaire and data on the factors the influenced adherence to cART.

The level of adherence was assessed after applying an adherence questionnaire: 18 -22 points (adherence $\geq 80 \%$ ) and under 18 points (non-adherence $<80 \%$ ) (17).

We used Fisher test for the statistical correlations, the value $\mathrm{p} \leq 0.05$ being considered statistically 
significant and the obtained results were synthesized in tables and figures.

\section{RESULTS}

The studied group included 71 patients and it was divided into two batches, depending on the route of HIV transmission: group A which included 48 pregnant women parenterally infected with HIV in early childhood and 23 pregnant women sexually infected with HIV.

The patients' characteristics are presented in Table 1.

TABLE 1. Characteristics of the patiens from the studied groups

\begin{tabular}{|c|c|c|c|c|}
\hline \multirow{2}{*}{$\begin{array}{c}\text { Patients' } \\
\text { characteristics }\end{array}$} & \multicolumn{2}{|c|}{ Group A } & \multicolumn{2}{c|}{ Group B } \\
\cline { 2 - 5 } & Median & $\begin{array}{c}\text { Media } \pm \\
\text { DS }\end{array}$ & Mediana & $\begin{array}{c}\text { Media } \pm \\
\text { DS }\end{array}$ \\
\hline $\begin{array}{c}\text { Maternal age } \\
\text { a } \begin{array}{c}\text { diagnosis of } \\
\text { HIV inf } \\
\text { (years) }\end{array}\end{array}$ & $13[3: 30]$ & $13.1 \pm 5.5$ & $23[14: 32]$ & $23.5 \pm 5$ \\
\hline $\begin{array}{c}\text { Maternal age } \\
\text { at delivery } \\
\text { (years) }\end{array}$ & $28[23: 33]$ & $27.6 \pm 2.2$ & $24[14: 34]$ & $25.9 \pm 5$ \\
\hline $\begin{array}{c}\text { Dura onf } \\
\text { diagnosis to } \\
\text { pregnancy } \\
\text { (years) }\end{array}$ & $15[0: 25]$ & $14.1 \pm 5.2$ & $1[0: 9]$ & $2.39 \pm 2.87$ \\
\hline
\end{tabular}

The median age of the patients at the time of diagnosis of HIV infection was 16 years [3:32] with statistically significant differences between the two groups $(\mathrm{p}=0.003)$.

The median duration of treatment was 12 years $[0: 24]$ and the median number of cART regimens was 3 [1:8].

For the prophylaxis of mother-to-child transmission of HIV infection, 59 patients $(83 \%)$ received cART throughout pregnancy without statistically significant differences between the two groups $(\mathrm{p}=0.2)$.

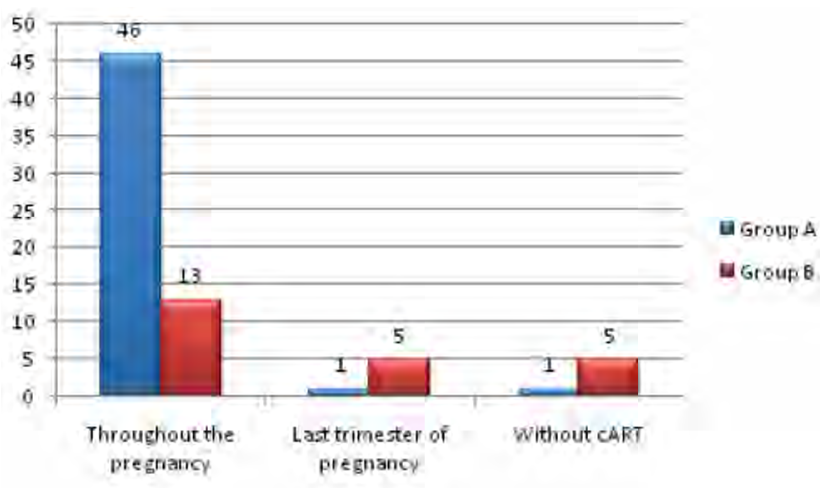

FIGURE 1. cART during pregnancy
From the 6 patients who did not receive cART during pregnancy, one patient belonging to group A refused cART and the other 5 patients, belonging to group $\mathrm{B}$, were diagnosed at the time of labor and delivery.

The most commonly used cART during pregnancy was Lamivudine/Zidovudine (3TC/ZDV) + Lopinavir/ Ritonavir (LPV/r) - 20 patients in group A (42.5\%) and 14 patients in group B $(77.7 \%)$

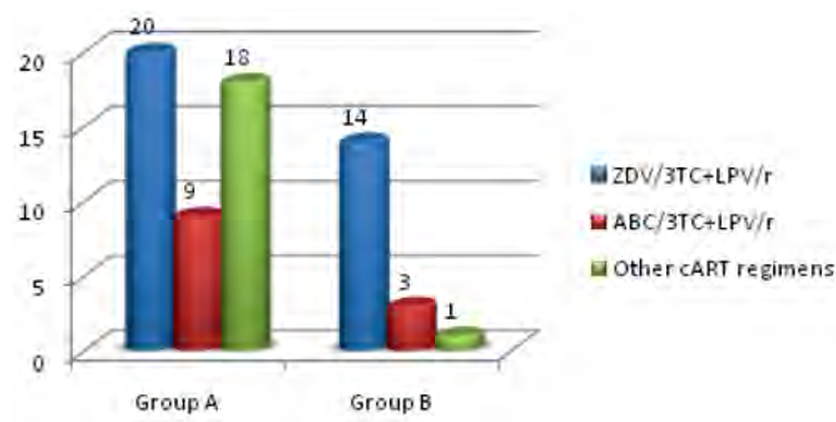

FIGURE 2. Antiretroviral therapies used during pregnancy

The level of adherence of the patients from the studied groups was assessed after applying an adherence questionnaire, which is completed periodically for all HIV-infected patients registered within CRC.

From the 65 patients who received cART during pregnancy, 21 were non-adherent to cART (32.3\%). We found that the proportion of non-adherent patients was higher in sexually infected mothers $(77.7 \%)$ compared to those parenterally infected, in early childhood (14.8\%), with statistically significant differences $(\mathrm{p}=0.001)$.

We identified some of the factors that could influence the level of patients' adherence to cART, comparing their impact in adherent patients (adherence $\geq 80 \%$ ) vs. non-adherent patients (adherence $<80 \%$ ).

One of the most important parameters through which adherence to cART can be assessed is the level of HIV viremia. Undetectable plasma viral load is a proof of the efficiency of cART, being correlated with adherence. In our study, the HIV viral load level was correlated with the level of adherence to cART $(\mathrm{p}=0.005)$.

The immunological evaluation of the pregnant women showed a low degree of immunosuppression with a mean CD4 lymphocytes of $497.6 \pm 279.8$ cells/ $\mathrm{mm}^{3}$, $43 \%$ of the patients with CD4 $>500$ cells $/ \mathrm{mm}^{3}$; without statistically significant differences between the two groups $(p=1)$. The degree of immunosuppression was not correlated with non-adherence to cART. 
Name and surname:

Date: Patient's signature:
Age: _ years Gender: $\square \mathbf{M} \square \mathbf{F}$

Evaluator's signature:

1. How much do you think that daily, correct and uninterrupted administration of cART, according to the doctor's recommendations, helps you to maintain your health? (choose only one answer)
very much 3
a lot 2
not much 1
not at all 0

2. In which positive way do you think antiretroviral drugs influence your life? (choose one or more answers):

they ensure my good health 3

they allow me to have a long and normal life 3

they decrease the risk of transmission to the partner 2

they decrease the risk of mother-to-child transmission 2

none 0

3. In which negative way do you think antiretroviral drugs affect your life? (choose only one answer)

I'm afraid I'll be exposed (I can be seen when I take my medication) 0

I risk losing my boyfriend/girlfriend 0

they affect my daily schedule 0

they always remind me that I'm a sick person 0

they give a bad mood 0

none 1

4. Did you skip taking your pills last weekend?

Yes 0

No 3

5. How many times did you miss taking your pills last month? (choose only one answer)
I didn't miss any 3
A single administration 3
Between 2 and 4 administrations 2
Between 4 and 8 administrations 1
More than 8 administrations 0

6. Did the same thing happen to you in the past few months?

Yes

No

7. Did it happen to have extra pills at the end of the month due to inconsistent administration ?
Yes, a lot 0
Yes, a few 1
No 2

8. Which administration is the most difficult? (choose only one answer)

The morning one

The afternoon one

The evening one

All of them

None of them

9. What do you do in order to remember to take your pills (choose one or more answers):

I set the alarm clock

I use pillbox in which I store the my scheduled doses of pills

I have my parents/partner/someone else to remind me

I use other daily activities (for instance daily meals)

I don't have a special method

Evaluation score:

Rating:

20-22 points = very good adherence $-95 \%$

Minimum accepted: 18 points = acceptable adherence $-80 \%$

Under 18 points = non-adherence, under $\mathbf{8 0 \%}$

FIGURE 3. Adherence questionnaire

Patients who were non-adherent to cART were advised by the psychologist, in order to identify the causes that led to the low adherence and the measures that can be taken to improve the level of adherence to cART. 


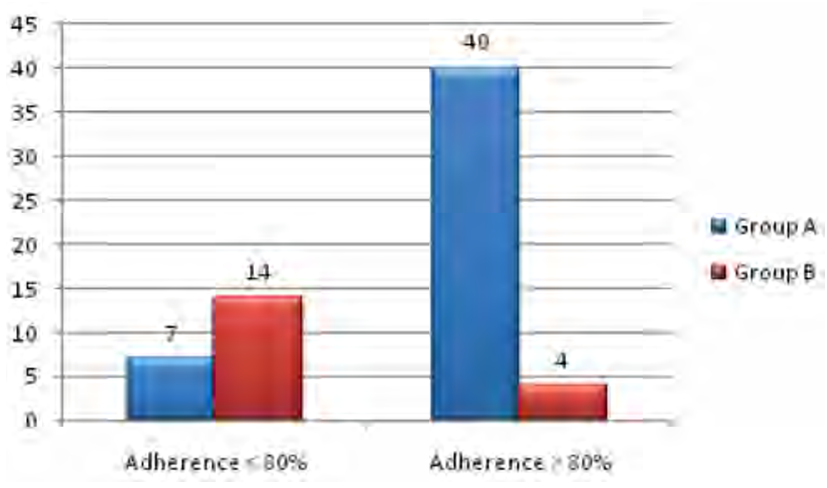

FIGURE 4. The level of adherence to cART within the two groups

TABLE 2. Factors that may influence the adherence to $C A R T$

\begin{tabular}{|c|c|c|c|c|}
\hline \multicolumn{2}{|c|}{ Factors that may influence the adherence to ARTC } & Adherence $<80 \%$ & Adherence $\geq 80 \%$ & p \\
\hline Educa & $\begin{array}{l}<8 \text { classes } \\
\geq 8 \text { classes }\end{array}$ & $\begin{array}{c}14 \\
7\end{array}$ & $\begin{array}{c}6 \\
38\end{array}$ & 0.004 \\
\hline $\begin{array}{l}\text { Environmental } \\
\quad \text { origins }\end{array}$ & $\begin{array}{c}\text { rural } \\
\text { urban }\end{array}$ & $\begin{array}{c}16 \\
5\end{array}$ & $\begin{array}{l}31 \\
13\end{array}$ & 1 \\
\hline Marital status & $\begin{array}{r}\text { unmarried } \\
\text { married/stable rela }\end{array}$ & $\begin{array}{c}3 \\
18\end{array}$ & $\begin{array}{c}5 \\
39\end{array}$ & 1 \\
\hline Socioeconomic status & $\begin{array}{c}\text { precar } \\
\text { bun }\end{array}$ & $\begin{array}{c}12 \\
9 \\
\end{array}$ & $\begin{array}{c}1 \\
43 \\
\end{array}$ & 0.002 \\
\hline $\begin{array}{c}\text { Maternal age at } \\
\text { delivery }\end{array}$ & $\begin{array}{l}\leq 26 \text { ani } \\
>26 \text { ani }\end{array}$ & $\begin{array}{c}15 \\
6 \\
\end{array}$ & $\begin{array}{l}10 \\
34\end{array}$ & 0.01 \\
\hline CART side e ects & $\begin{array}{l}\text { Presence of side e ects } \\
\text { No side e ects }\end{array}$ & $\begin{array}{l}14 \\
7\end{array}$ & $\begin{array}{l}12 \\
32\end{array}$ & 0.04 \\
\hline
\end{tabular}

TABLE 3. Correlation between immuno-virological status and the level of adherence

\begin{tabular}{|c|c|c|c|c|}
\cline { 3 - 5 } \multicolumn{2}{l|}{} & $\begin{array}{c}\text { Adherence } \\
<\mathbf{8 0 \%}\end{array}$ & $\begin{array}{c}\text { Adherence } \\
\mathbf{2 8 0 \%}\end{array}$ & $\mathbf{p}$ \\
\hline \multirow{2}{*}{ VL-HIV } & $<50$ copies $/ \mathrm{ml}$ & 4 & 32 & \multirow{2}{*}{0.005} \\
& $>50$ copies $/ \mathrm{ml}$ & 17 & 12 & \\
\hline \multirow{2}{*}{ CD4 } & $<200$ cells $/ \mathrm{mm}^{3}$ & 5 & 3 & 0.2 \\
& $>200$ cells $/ \mathrm{mm}^{3}$ & 16 & 41 & \\
\hline
\end{tabular}

\section{DISCUSSIONS}

Adherence to cART plays an essential role in the management of HIV-positive patients. cART in HIVpositive pregnant women is indicated for preventing mother-to-child transmission of HIV infection and for preventing the progression of maternal disease. cART must be adapted to a maximum maternal benefit, taking into account the fetal benefit $(18,19)$.

Various studies from all over the world report several factors that may influence the level of adherence to cART, some of them being evaluated in the study we performed.
An extensive study was conducted between 2001 and 2005 in medical centers from Chicago, New York, Houston, Boston/Worcester and San Juan, Puerto Rico, which examined cART use and adherence in HIV-positive women during the third trimester of pregnancy and six-month postpartum. Adherence to cART was assessed through a self-report method. During the third trimester of pregnancy, $61 \%$ of patients (188/309) had complete adherence to cART, defined as adherence to all medications taken in the last two days and no missed doses within the last month. Factors associated with non-adherence included advanced maternal disease, higher HIV viral load, alcohol use and smoking. At six-month postpartum, $55 \%$ of patients had good adherence to cART. The results of this study indicated that HIV-infected women had better adherence to cART during pregnancy than postpartum, probably due to the motivation to reduce the risk of vertical transmission and/or intensive antepartum surveillance (20).

In the study we conducted, pregnant women parenterally infected with HIV-1 in early childhood had a 
better adherence to cART than those who were sexually infected.

Another study performed in South Africa (Eastern Cape) included 1,709 HIV-positive pregnant women. $69 \%$ of these women had a high level of adherence to cART. Marital status, smoking, alcohol consumption and non-disclosure of HIV status were independent predictors of non-adherence. The analysis of the qualitative data revealed that the cART side effects, social stigma, forgetfulness were the main factors associated with non-adherence (12).

51 studies involved 20,153 HIV-positive pregnant women. Most studies were performed in the United States (27\%), Kenya (16\%), South Africa (10\%) and Zambia (10\%). The threshold that defined a good adherence to cART varied across studies ( $>80 \%$, $>90 \%,>95 \%, 100 \%)$. A common analysis of all studies indicated that $73.5 \%$ of pregnant women had good adherence $(>80 \%)$. The proportion of women with good adherence to treatment was higher during the antepartum period than during postpartum. Factors associated with non-adherence were emotional, physical and economic stresses, depression (especially postpartum), alcohol or drug use, pill burden (21).

In our study we identified the following factors associated with low adherence to cART: education $(p=0.004)$, socioeconomic status $(p=0.002)$, maternal age at delivery $(\mathrm{p}=0.01)$ and cART side effects $(\mathrm{p}=0.04)$.

\section{CONCLUSIONS}

Pregnant women infected with HIV-1 in early childhood had a higher level of adherence to cART compared to those sexually infected.

The correlation between the level of adherence to cART and HIV viremia was statistically significant.

The main factors associated with non-adherence were low level of education, low socioeconomic status, young maternal age, the presence of cART side effects.

Conflict of interest: none declared Financial support: none declared

\section{REFERENCES}

1. https://www.who.int/news-room/fact-sheets/detail/hiv-aids. [Online] November 15, 2019. [Cited: August 19, 2020.].

2. Nthala V, Makasa M, Hazeemba A, Sitali D. Adherence to ART Among Pregnant Women Living with HIVIAIDS in Lusaka Urban. Journal of Public Health International. 2019;1(3).

3. European Guidelines for treatment of HIV-positive adults in Europe. October 2018.

4. The European Collaborative Study. Mother-to-child transmission of HIV infection in the era of highly active antiretroviral therapy. Clin Infect Dis. 2005;40:458-65.

5. Cooper ER, Charurat M, Mofenson L et al. Combination antiretroviral strategies for the treatment of pregnant HIV-1-infected women and prevention of perinatal HIV-1 transmission. J Acquir Immune Defic Syndr. 2002;29:484-94.

6. Mandelbrot L, Tubiana R. No perinatal HIV-1 transmission from women with effective antiretroviral therapy starting before conception. Clin Infect Dis. 2015:61:1715-25.

7. Hampanda KM, Abuogi LL, Ahmed Y. HIV-Positive Women Taking Lifelong Antiretroviral Therapy Report Better Adherence Than Women Taking Short-Course Prophylaxis During and After Pregnancy Under PMTCT Program Option A in Lusaka, Zambia. International Journal of MCH and AIDS. 2017;6(1):28.

8. https://aidsinfo.nih.gov/guidelines/html/3/perinatal/0. [Online] 2018. [Cited: August 19, 2020].

9. Gilbert EM, Darin KM, Scarsi KK, McLaughlin MM. Antiretroviral pharmacokinetics in pregnant women. Pharmacotherapy. 2015; 35:838-55.

10. Iliyasu Z, Kabir M, Abubakar IS, Babashani M, Zubair ZA. Compliance to antiretroviral therapy among AIDS patients in Aminu Kano Teaching Hospital, Kano, Nigeria. Niger J Med. 2005; 14(3):290-294.

11. Nachega JB, Marconi VC, van Zyl GU, GardnerEM, PreiserW, Hong SY et al. HIV treatment adherence, drug resistance, virologic failure: evolving concepts. Infect Disord Drug Targets. 2011;11:167-174.

12. Adeniyi OV, Ajayi Al, Ter Goon D, Owolabi EO, Eboh A, Lambert J. Factors affecting adherence to antiretroviral therapy among pregnant women in the Eastern Cape, South Africa. BMC Infect Dis. 2018; 18(1):175.

13. Shubber Z, Mills EJ, Nachega JB et al. Patient-Reported Barriers to Adherence to Antiretroviral Therapy: A Systematic Review and Meta-Analysis. PLoS Med. 2016;13(11):e1002183.

14. Azia IN, Mukumbang FC, Van Wyk B. Barriers to adherence to antiretroviral treatment in a regional hospital in Vredenburg, Western Cape, South Africa. Southern Afr. J HIV Med. 2016;17(1):1-8.

15. Mukui IN, Williamson J, Wamicwe JN et al. Rates and predictors of non-adherence to antiretroviral therapy among HIV-positive survey, 2012. PLoS One. 2016;11(12):e0167465.

16. Fowler MG, Qin M, Fiscus SA et al. Benefits and risks of antiretroviral therapy for perinatal HIV prevention. N Engl J Med. 2016; 375:1726-1737.

17. Drăgănescu $M$, lancu $A V$, Modrigan $M$, Arbune $M$. Aderența la tratamentul antiretroviral și trăsăturile de personalitate ale pacienților cu infecție HIV. Probleme de patologie infecțioasă la frontiere. Conferința Națională cu participare Internatională, Galați, 7-9 iunie 2018, Editura GUP, 2018.

18. Brocklehurst $P$. Interventions for reducing the risk of mother-to-child transmission of HIV infection. Cochrane Database Syst Rev. 2002.

19. Lyall EG, Blott M, de Ruiter A, Hawkins D, Mercy D, Mitchla Z et al. Guidelines for the management of HIV infection in pregnant women and the prevention of mother-to-child transmission. HIV Med. 2001; 2:314-34.

20. Mellinsa CA, Chub C, Maleec K et al. Adherence to antiretroviral treatment among pregnant and postpartum HIV-infected women. AIDS Care. 2008;20(8):958-968.

21. Nachegaa JB, Uthmane OA, Andersong J, Peltzer $\mathrm{K}$ et al. Adherence to antiretroviral therapy during and after pregnancy in low-income, middle-income, and high-income countries: A systematic review and meta-analysis. AIDS. 2012;26(16):2039-2052. individuals in Kenya: Results from the second Kenya AIDS Indicator 